\title{
Bartter syndrome with hypocalcemia
}

INSERM

\section{Source}

INSERM. (1999). Orphanet: an online rare disease and orphan drug data base. Bartter syndrome with hypocalcemia. ORPHA:263417

Bartter syndrome with hypocalcemia is a type of Bartter syndrome (see this term) characterized by hypocalcemia, hypomagnesemia and hypoparathyroidism along with features of Henle's loop dysfunction (polyuria, hypokalemic alkalosis, increased levels of plasma renin and aldosterone, low blood pressure and vascular resistance to angiotensin II). Bartter syndrome with hypocalcemia is a very rare manifestation of autosomal dominant hypocalcemia (ADH; see this term) 